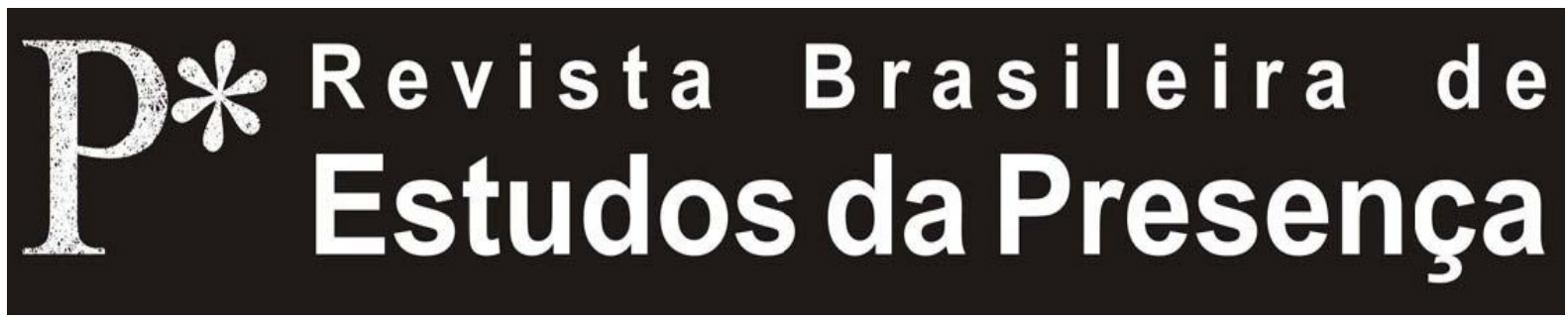

DOI - http://dx.doi.org/10.1590/2237-266034764

ISSN 2237-2660

\title{
Uma Arte do Encontro
}

\author{
Éric Vautrin \\ Normandie Université - Unicaen-LASLAR, Caen, França
}

RESUMO - Uma Arte do Encontro ${ }^{1}$ - A partir da abertura para pesquisas dos arquivos da segunda parte da vida de Grotowski, este texto se debruça sobre as concepçóes de teatro do mestre polonês, nas quais ele o descreve como a arte do encontro. Trata-se, ao mesmo tempo, de colocar essa proposição nas interrogações de uma época e de mostrar como esse encontro é o anátema que reverterá as perspectivas tanto sobre a arte do ator, quanto sobre a criação e as relaçóes teatrais. Enfim, essas pesquisas sobre o teatro como arte do encontro têm continuidade hoje por intermédio do Open Program, um dos dois grupos do Workcenter of Jerzy Grotowski and Thomas Richards e, notadamente, suas criaçóes em torno do poeta americano Allen Ginsberg, autor cuja poesia pretende, da mesma forma, um encontro com o outro e com o mundo.

Palavras-chave: Ator. História da Performance. Processos de Criação. Relaçóes Teatrais. Memória.

ABSTRACT - The Art of the Encounter - As the archives from the second half of Grotowski's life were made available, this text focuses on the Polish master's conceptions of theatre where he describes theatre as the art of the encounter. This paper simultaneously places this proposition in the context of questions of a specific time period, and reveals how this encounter is the anathema that will revert viewpoints both about the art of acting and the creation of theatrical relations. These researches on theatre as the art of the encounter continue today through the Open Program, one of the two groups of the Workcenter of Jerzy Grotowski and Thomas Richards, and, notably, their creations around American poet Allen Ginsberg, an author whose poetry intends, in a similar way, to encounter the other and the world.

Keywords: Actor. History of Performance. Creative Processes. Theatre Relations. Memory.

RÉSUMÉ - Un Art de la Rencontre - À l'occasion de l'ouverture à la recherche des archives de la seconde partie de la vie de Grotowski, ce texte revient sur les conceptions du théâtre du maître polonais qu'il décrit comme un art de la rencontre. Il s'agit à la fois de replacer cette proposition dans les interrogations d'une époque et de montrer comment cette "rencontre" est l'anathème qui renversera les perspectives tant pour l'art de l'acteur que pour la création et la relation théâtrale. Enfin, ces recherches sur le théâtre comme art de la rencontre se poursuivent aujourd'hui à travers l'Open Program, l'un des deux groupes du Workcenter of Jerzy Grotowski and Thomas Richards, et notamment leurs créations autour du poète américain Allen Ginsberg, auteur dont la poésie se veut également l'occasion d'une rencontre avec l'autre et avec le monde.

Mots-clés: Acteur. Histoire de la Performance. Processus de Création. Relation Théâtrale. Mémoire. 
Em março de 2012, a coleção de arquivos de Jerzy Grotowski, conservada no IMEC $^{2}$, via terminado seu inventário e tornava-se acessível aos pesquisadores. A coleção é composta de documentos sobre a trajetória de Grotowski após sua partida da Polônia, mais especificamente no Teatro das Fontes (a partir de 1980), no Objective Drama Project (desde 1986) e, posteriormente, no quadro do Workcenter, de Pontedera. A coleção reúne notas preparatórias, transcriçóes de cursos e conferências, textos de referência e fotografias ${ }^{3}$. E junta-se, assim, aos arquivos de seu itinerário polonês conservado no Centro dos estudos sobre a obra de Jerzy Grotowski e de pesquisas teatrais e culturais ${ }^{4}$ de Wroclaw, na Polônia. $\mathrm{Na}$ ocasião da abertura da coleção, foi organizada, em Caen, uma semana com o Workcenter e o Open Program, e uma jornada de estudos intitulada Uma Arte do Encontro, reunindo pesquisadores e praticantes 5 .

O precioso inventário, realizado pela arquivista Pascale Butel com a ajuda de Magda Zlotowska (colaboradora próxima de Grotowski) e dos herdeiros de Grotowski, que são os atuais codiretores do Workcenter, Thomas Richards e Mario Biagini, permite reconsiderar as contribuiçóes de Grotowski à arte do teatro. O presente texto gostaria de retornar a essa herança, recolocando sua obra no conjunto de preocupaçóes de uma época, para perceber como suas pesquisas se dirigem náo apenas a uma arte do ator de disciplina estrita ou a espetáculos de estética pobre, fórmulas bastante comuns pelas quais é lembrado e estudado, mas a uma concepção da arte e do teatro que se manifesta ainda hoje, e, finalmente, a uma maneira de ser e de viver que ultrapassa seu tempo e o campo estrito da arte (Lista, 1997, p. 195). Essa apreensão renovada da obra e das pesquisas de Grotowski permite recolocá-las na história do teatro e das artes performativas recentes, assim como reconsiderar o projeto do Workcenter e seu desenvolvimento atual como um lugar e um espaço onde se conjugam pesquisa e criação, e não apenas como um centro de pesquisas avançadas sobre $\mathrm{o}$ ator.

É preciso voltar entáo àquilo que motiva e estrutura essas pesquisas. Antes dos trabalhos sobre o ator santo, sobre as memórias dos seres e dos textos, há uma afirmação, uma pequena frase simples cuja aplicaçáo vai sem dúvida conduzir o conjunto das pesquisas de Grotowski. É a partir dela que se desenrola o conjunto de sua obra e que sua herança se descobre. Escolhida como título de uma 
entrevista publicada em francês na edição francesa de Em busca de um teatro pobre, anuncia: "[...] a essência do teatro é um encontro" (Grotowski, 1971, p. 55).

O teatro como encontro - encontro, entáo, antes de toda comunicação, troca intelectual ou confrontação - é o anátema que provoca a inversão radical que marcará sua teorização da atuação. É também o termo de uma época, o pós-guerra, durante a qual outros modos de relaçáo entre cena e plateia, entre atores e espectadores, entre artistas e cidade, são esperados, desejados e experimentados. No e pelo encontro, o ator não representa, não exterioriza, expóe-se na sua ação: é o ator de Grotowski na condição de performer. Ele não se projeta no texto, traz o texto para si; é Antoine Vitez e, logo após, Klaus-Michael Grüber que fazem falar o texto como uma matéria enigmática e decididamente estrangeira, é Tadeusz Kantor que confunde textos de Witkiewicz ou de seus atores com suas próprias lembranças. Assim, a afirmaçáo do teatro como encontro pertence a uma época que interrogou a noçáo de autoridade e os modos de relações humanas e coletivas, e, finalmente, as relações entre a arte e a vida.

No entanto, Grotowski dá a essa intuição uma versão singular. Quando sua reflexão se concentrará no ator, ele fará do texto um bisturi para revelar tanto seus instintos quanto sua lucidez, tanto suas fraquezas quanto suas potencialidades:

[...] a essência do teatro é um encontro. Aquele que realiza um ato de autorrevelação é, por assim dizer, aquele que estabelece um contato consigo mesmo. Isto é: uma confrontação extrema, sincera, disciplinada, precisa e total - não somente uma confrontação com seus pensamentos, mas uma confrontação que implica todo seu ser, desde seus instintos e seu inconsciente até seu estado mais lúcido (Grotowski, 1971, p. 55).

O encontro, em cada momento de sua realização, é aqui entendido num sentido forte e ampliado. Não é apenas o kairos, a ocasião, a circunstância inesperada que me coloca em relaçáo com alguma coisa ou alguém, é o tempo muito específico da confrontação com outrem, seres, textos ou memórias, ou consigo mesmo - uma confrontação, como dizia Mario Biagini numa conferência ministrada na universidade de Caen (Biagini, 2013), que quer dizer, então, mais um face a face do que um enfrentamento, e envolve todo o ser, em suas dimensôes orgânicas ou biológicas e espirituais, ou, em todo 
caso, já que Grotowski parecia desconfiar dessa palavra no fim de sua vida, intelectuais, técnicas e morais ou imaginativas.

Essa arte do encontro tem dois aspectos ou duas consequências: de um lado, é aquilo que Grotowski traz como próprio à arte do teatro e que o faz deslocar partes inteiras do artesanato teatral; de outro lado, é por esse viés que a arte do ator engendra ou reencontra uma arte do espectador. Esses dois aspectos de suas pesquisas, intimamente ligados - o trabalho de criação e a relação com o espectador - são também os pontos pelos quais sua obra e seu pensamento se ancoram em sua época.

Com efeito, se Grotowski pouco a pouco concentrou sua atenção no ator, os primeiros momentos de sua reforma teatral fixavam-se tanto na atuação e na mise en scène quanto no texto e no espectador. Ele pensou um espectador que não era mais apenas aquele a quem era destinado o espetáculo, através de todas as formas de endereçamento possíveis, nem aquele que recebia e interpretava, por sua própria conta, imagens e textos cênicos, mas como um dos termos do drama. É claro que os simbolistas já haviam feito do espectador o artista de um teatro mental, e Meyerhold, do Teatro da convenção consciente, havia descrito o espectador como o quarto criador do teatro, com o autor, o ator e o diretor - por exemplo. Mas, a proposta de Grotowski é diferente: não se trata apenas da capacidade do espectador de realizar suas próprias simbolizaçóes, completando à sua maneira as propostas da cena, mas de uma dramatização de sua presença, sua inclusão na ficção, como agente, mudo e atento, tanto da ficção narrada como da cenografia - tendo um papel tanto no espaço da atuaçáo, como presença coletiva, quanto na ficção, como figura. Essa concepção de um espectador que tem uma presença dramatizada é indissociável da busca de uma atuaçáo como autor-revelação.

Essa imbricação da arte do ator e da arte do espectador inscreve a herança de Grotowski em um momento artístico e intelectual mais amplo. Os anos 1960 e 1970 são marcados, como já lembramos, pela pesquisa de uma teatralidade renovada, aberta à experiência humana como um todo e que vai passar por novas formas de implicaçóes do artista na sua obra e por novas maneiras de interpelar o espectador. Os primeiros textos de Grotowski (1955-1965, dos primeiros escritos aos primeiros anos do Teatro Laboratório) são contemporâneos das conferências e dos events de John Cage, dos happenings de Allan 
Kaprow nos Estados Unidos ou das primeiras obras dos pioneiros da poesia sonora na França ${ }^{6}$. A década que as criaçóes teatrais do Teatro Laboratório cobrem é aquela do movimento de experimentaçôes que chamamos, retrospectivamente, de performance. Não se trata entáo de uma influência ou de uma anterioridade de tal ou tal abordagem, nem mesmo de semelhante retorno das vanguardas dos anos 1900-1910 às artes cênicas pós-1945, trata-se, sobretudo, de uma renovaçáo geral das propostas de espetáculo a partir de pelo menos dois termos: de um lado, uma mudança de relaçáo entre a cena e seus espectadores, relação que tende à inclusão ou à participação, e, de outro lado, a uma abertura da arte à vida, menos como um problema de estilo e de estética ou mesmo de discurso, e mais como uma prática que se define, sobretudo, como uma maneira singular e experimental de viver. É nessa grande reviravolta das práticas que Grotowski ao mesmo tempo se inscreve e se singulariza, e que marcou duradouramente a arte teatral. Enfim (e a isso voltaremos), não é insignificante que, desse ponto de vista, Mario Biagini escolha os textos de Allen Ginsberg, autor americano da dita beat generation, para seguir esse trabalho com o Open Program

A performance deve ser, sem dúvida, compreendida como uma teatralidade estendida a todo ato, artístico ou não; mas, a singularidade de Grotowski nos tempos do Teatro Laboratório vem do fato de que, contrariamente a uma parte de seus contemporâneos e após diversas tentativas relatadas por Bénédicte Boisson, ele náo abandona o dispositivo dramático - nem o texto, nem a ficção, nem a simbolização teatral. Ao contrário, ele os mantém para deles fazer instrumentos de conhecimento de si mesmo: tornam-se tanto um modo de descrever o mundo como uma maneira de se conhecer; ou tornam-se, sobretudo, o modo de reencontrar o que une profundamente, confusamente, o si mesmo - todo si mesmo, se assim se pode dizer, vida interior, experiências, memórias - e as forças, potências e violências do real. O real não é então esse ou aquele complexo de signos que o meio nos fornece, não é o que acontece no momento de nossa percepção; mas é, ao mesmo tempo, o atual, o passado, as narrativas e os mitos; isto é, como escreve Marie-Madeleine MervantRoux $^{8}$, todas as formas de estruturação social do tempo. O trabalho do ator, composto de uma disciplina física estrita que visa a torná-lo disponível à representação e ao texto, agora bisturi de sua interiori- 
dade, consiste em revelar como nele se inscrevem essas estruturaçóes sociais do tempo. Assim, o ator se descobre, no duplo sentido de se desnudar e de se explorar - e por essa mesma atuaçáo o espectador é convidado a também se descobrir, a escutar o que em si ressoa. $\mathrm{O}$ que é atualizado não pertence nem a um nem a outro, mas os religa um ao outro. Não é, como em Cage ou Kaprow, o aqui e agora que é explorado em todas suas dimensôes, o contexto imediato ou aquilo que é partilhado, mas o aqui e agora de um texto cujas ressonâncias, através de uma experiência ao mesmo tempo pessoal e coletiva, se tornam uma abertura em direçáo a outras formas do tempo.

Assim, o encontro não é somente, em Grotowski, direcionado ao outro, direcionado ao contexto comum ao ator e ao espectador (à maneira de Cage ou Krapow) ou ao contexto sociopolítico dessa confrontação (à maneira de Yoko Ono ou de Marina Abramovic) - mas é igualmente direcionado ao próprio ator. Para preparar o encontro, o ator é levado a engajar seu ser, e náo apenas a maneira de se apresentar. Este é o ponto de partida, a razão que vai guiar a arte do ator e sua relação consigo mesmo, assim como sua relação com os outros artistas participantes da representação teatral: "[...] o teatro é também um encontro entre criadores. Sou eu mesmo, como diretor, que sou confrontado com o ator, e a autorrevelaçáo de um ator me dá a revelação de mim mesmo" (Grotowski, 1971, p. 55). Dramaturgia e mise en scène são pensadas através do mesmo princípio:

[...] os atores e eu mesmo somos confrontados com o texto. [...] Meu encontro com o texto se assemelha ao meu encontro com o ator, e o encontro dele com o texto. [...] As obras [de Marlowe ou de Calderón] me fascinam porque nos dão a possibilidade de uma confrontação brutal e repentina entre, de um lado, as crenças e as experiências de vida das geraçôes precedentes, e, de outro, nossas próprias experiências e nossos próprios preconceitos (Grotowski, 1971, p. 55).

Trata-se de um encontro do ator consigo mesmo, de um encontro do ator e do diretor, encontrando nessa relação de atenção mútua a um texto a ocasiáo e os meios de um conhecimento de si mesmos; e encontro, então, na exigência e na integridade desse trabalho, com um texto, e, por saltos ou continuidade, encontro com uma memória dos tempos, do presente, do atual, do passado e dos mitos. Os encontros que guiam o teatro de Grotowski não visam apenas o conhecimento de si, à maneira da psicanálise, ou, ao con- 
trário, a atualização das histórias e mitos: o princípio ativo, se assim podemos dizer, é exatamente a confrontação, com acentos trágicos, isto é, inevitáveis e radicais, de si com outras memórias, de suas próprias memórias com outras nas quais estamos presos, mas que não nos pertencem. A arte do ator santo e a arte da mise en scène do teatro pobre náo se compreendem sem uma arte do encontro na qual o espectador não é um convidado, mas aquele que aceita reencontrar, através da representaçáo, como o ator e o diretor a reencontraram através do texto, uma experiência social do tempo.

Colocar em contato a arte do ator e a arte do espectador é igualmente um meio de inscrever as pesquisas atuais do Workcenter em uma continuidade com o trabalho de Grotowski, de outra maneira, ou de uma maneira mais abrangente, em relação àquela da disciplina específica do ator. Aqui, a herança de Grotowski não é unicamente disciplinar - seria assim demasiado morna e fria. A questáo é sabida - o Workcenter é, à sua maneira, um espaço de encontros, entre seres cujas histórias e culturas são diferentes - e o Open Program deixa claro o que ele é: um espaço aberto. Há pouco mais de 10 anos, e pela iniciativa de Grotowski, o Workcenter propóe novamente certas formas de espetáculos públicos. Ele convida seus espectadores a encontrar seu trabalho que foi por muito tempo mantido fechado, à parte, que esteve inscrito no longo tempo destinado à pesquisa e ao estudo.

Mario Biagini escolheu então as obras do poeta americano Allen Ginsberg para alimentar os espetáculos do Open Program. Ginsberg não tem nada de estrangeiro às problemáticas que acabamos de evocar. Poeta-testemunha de seu mundo, descrevendo uma América presa entre suas guerras e seus grandes espaços, entre poderosas energias vitais e suas duras misérias sociais, ele recupera as tradiçóes orais advindas da diáspora negra para compor seus longos poemas, descrevendo a América e seus próprios estados, emoçóes, inquietudes e oraçóes. Pela prosódia, pela escansão inspirada nos cantos negros, busca uma conexão com o cosmos, um modo de se inscrever novamente, à maneira de um xamá, nos ritmos e geometrias do mundo. Não é, no entanto, uma ode à natureza contra a loucura inconsciente das cidades, por exemplo. Nos seus textos, tanto a natureza quanto a cidade são tal como são, lugares e meios para se reencontrar consigo mesmo. Assim, o poeta não contesta as formas de sua época, mas 
tenta inverter a relação com as mesmas; é a violência do homem e da sociedade que ele tenta transmutar de acordo com aquilo que o cerca, pela palavra, em todas as suas dimensóes descritivas, musicais e rítmicas. Há em Ginsberg a tentativa de colocar o mundo e seu espírito em acordo, de trazer o mundo o mais perto de si, em uma relação imediata e franca, mas ao mesmo tempo há a tentativa de dobrar a velocidade do mundo globalizado que a América projeta entáo dominar, as velocidades alucinantes da economia de mercado generalizada e dos meios de comunicação eletrônica que o mundo está descobrindo, de dobrá-las incluindo nelas, numa visão mais larga, outras rotinas, outros caminhos que abririam tanto para o passado quanto para o cosmos. Toda a obra de Ginsberg é, assim, a tentativa de reencontrar, pela via do ritmo, da prosódia e da memória negra, uma experiência social do tempo humano que ele opóe aos ritmos infernais da indústria e da comunicação imediata.

Mario Biagini encontra Allen Ginsberg no caminho dos cantos populares americanos do sul dos Estados Unidos, um caminho iniciado graças a um dos atores do Open Program, Lloyd Bricken, músico americano, e continuado graças aos arquivos sonoros do antropólogo do folclore Alan Lomax ${ }^{9}$. Esses cantos têm uma história muito particular: ressurgem das tradições africanas advindas do tráfico negreiro, e são originados de uma mestiçagem complexa e múltipla de tradiçóes e de culturas, notadamente crioulas. Sáo, sobretudo, cantos de antes da cultura, no sentido em que a entendemos hoje; sua finalidade era de fato prática, senão prosaica. Cantos dos prisioneiros de retorno à prisão, após a jornada de trabalhos forçados, dando à esperada liberdade os traços de uma bela mulher, cantos dos lenhadores que dáo ritmo ao gesto coletivo em torno da grande serra - ritmo que, se náo é seguido estritamente, pode fazer escapar a lâmina e ferir os lenhadores -, cantos dos camponeses colhendo o algodão sob o sol, cantos enfim entoados após a missa, na ou diante da igreja, que reúnem a comunidade, tornando-a mais unida, após ter sido instituída pela autoridade do padre. As noçóes de justeza ou de tecnicidade desses cantos importam menos do que sua capacidade de envolver os corpos e os seres em suas obras. Assim, não é surpreendente ouvir, nas gravaçôes de Lomax, vozes de avós, depois da missa, vozes desafinadas que com certeza não são as mais delicadas do grupo, mas que são certamente as mais envolventes ou 
inebriantes, e que vão, de fato, lançar os cânones e envolver todos e cada um no canto e na dança.

Um canto leva a uma ação: eis aí como se articula e se organiza o trabalho dos atores do Open Program. O sentido de um canto náo é distinto do que ele provoca e movimenta dentro do indivíduo. Mas, exatamente por isso, encontro em mim mesmo algo de uma memória que não me pertence. Esses cantos são menos a descrição de uma história do que uma tensão propriamente humana - aqui entre esperanças e violências, entre um momento duramente material e um poder inteiramente humano de projeção em um espaço tanto político como espiritual ${ }^{10}$. Essa memória que sustenta esses cantos não é a história, não encontramos no canto e na escuta o que realmente aconteceu - seria odioso pensar assim, essas violências nos são, felizmente, estrangeiras e não podemos encará-las senão de longe, confusamente. $\mathrm{O}$ que se revela não é o que realmente aconteceu, mas a marca concreta de uma ação inteiramente humana, uma ação conduzida por uma forma de resistência posta à prova e uma capacidade de enchantement [encantamento] - a palavra, tanto francesa quanto portuguesa, é singularmente precisa. Essa memória é mais um encontro do que uma narrativa ou um testemunho, um encontro entre uma ação passada e o que em mim ressona com ela, o que em mim a contém, a permite, conhece-a.

É aí que Ginsberg encontra Grotowski, ou Grotowski encontra Ginsberg. Ao encontrar em si os traços ou as condições de possibilidade de uma memória arcaica ou antiga, me encontro e, ao mesmo tempo, estendo minha existência entre esses dois polos que são a terra material e o espaço ou o tempo espiritual - uma espiritualidade que não é talvez uma transcendência, mas um encontro entre meu tempo e os ritmos do cosmos.

Mas há ainda outra história, outro estrato. Esses cantos populares do sul dos Estados Unidos vão se tornar blues, depois jazz, depois rock. Do canto coral ao canto de alguém para os outros, depois, do canto para outros ao canto de si para si, com essa guitarra elétrica que não produz som, mas que difunde sua música ao próprio guitarrista e que está, então, em posição de se escutar. É um caminho que vai de uma poesia prática e coletiva, inscrita no real, a uma poesia de si para si; que vai do artesanato à cultura midiática e industrial. Ora, os espetáculos do Open Program quebram, ao seu modo, essa lógica 
da indústria e do individualismo. Eles lembram um rock das origens, um rock não táo antigo, o de um Dylan, de um Neil Young ou de uma Janis Joplin, vindo de uma época quando a música estava em contato com aquilo que a cercava, como uma resposta à sociedade que a via nascer e se expressar. Volta para trás, de hoje até um pouco antes, volta que parece ter traços nostálgicos e empáticos, em direção aos anos em que se levantavam, ainda de outra maneira, revolta e esperança, provação e encantamento, violências e empatias. Pois há nesses espetáculos de ritmos vivos uma empatia proposta ao público: ao mesmo tempo envolvimento feito pelos cantos e encontro empático, sem distância, sem ironia, sem pensamentos subliminares, com aquilo que se passa em cena. E desse encontro com o espetáculo, e dessa projeção nos anos 1970, soam os ecos das memórias de cantos antigos e o acesso a outras ressonâncias entre si mesmo e o mundo.

A arte do ator e a arte do espectador estão aqui, mais uma vez, ligadas. $\mathrm{O}$ ator, com Grotowski e depois dele, não se projeta fora de si mesmo e não se deixa ser uma forma maleável à disposiçáo de outro além dele mesmo, seja diretor ou artista plástico. $\mathrm{O}$ ator, aqui, faz do teatro a ocasião de um encontro consigo mesmo, que é também um encontro com um tempo humano. O que ele mostra e propóe ao espectador, então, não é uma forma ou uma narrativa, ou não é apenas isso, mas também um encontro-partilha nascido de tudo o que ele traz dentro de si e divide com os artistas e com outros seres, ausentes e, não obstante, surpreendentemente presentes através das músicas vindas do passado até nós por caminhos insólitos. O teatro não é mais, então, o lugar de uma ilusão crítica ou de um discurso, mas um espaço aberto para o tempo em que se exploram os elos entre matérias díspares, memórias esquecidas e seres inesperados. 


\section{Notas}

${ }^{1}$ Este artigo é uma versão do texto publicado simultaneamente em francês em Attisani (2013).

${ }^{2}$ Institut Mémoires de l'Édition Contemporaine, é uma instituição de arquivos e de pesquisas instalada em Paris e em Saint-Germain la Blanche Herbe (Baixa-Normandia, França) que conserva, inventaria e torna acessível à pesquisa coleçóes de arquivos de autores e outros. Disponível em: <http://www.imec-archives.com>.

${ }^{3}$ Apresentação da coleção disponível na internet: <http://www.imec-archives.com/fonds_ archives_fiche.php?i=GRW>.

${ }^{4}$ Disponível em: <http://www.grotcenter.art.pl>.

${ }^{5}$ Jornada proposta por Éric Vautrin (Universidade de Caen Basse-Normandie/Laslar) com o apoio do Laslar (Caen), da APP (Rennes 2) e de HAR Paris-Ouest Nanterre, e em associaçáo com o CDN de Basse-Normandie, 24 de março de 2012, St. Germain-la-blanche-herbe.

${ }^{6}$ Notaremos que do mesmo modo que estes revisitavam à sua maneira as experiências dos anos 1910 e 1920, Grotowski recuperava e prolongava as questóes dos primeiros mestres da mise en scène por semelhante movimento duplo de retorno e de continuidade.

${ }^{7} \mathrm{O}$ Workcenter of Jerzy Grotowski and Thomas Richards é composto de duas equipes de pesquisas, o Focused Research Team in Art as Vehicle dirigido por Thomas Richards e o Open program mantido pelo diretor associado do Workcenter, Mario Biagini. O Open program reúne onze atores vindos de várias partes do mundo; seus trabalhos procuram notadamente facilitar e encorajar as trocas entre o Workcenter e a sociedade, se debruçando precisamente sobre a copresença e as relaçóes entre atores e espectadores.

${ }^{8} \mathrm{O}$ "real" é a estruturação social do tempo: o ritmo do dia e da noite, o calendário anual, a memória do passado transcrita pela história; é a organização social do espaço: a topografia da cidade (com suas moradias, suas praças, seus edifícios) e, mais largamente, a geografia. Esse 'real', culturalmente organizado, integra naturalmente elementos míticos. Não se pode falar de oposiçáo entre o irreal absoluto da cena e o real absoluto dos espectadores (Mervant-Roux, 2010, online).

${ }^{9}$ Uma parte das coletas sonoras desse célebre antropólogo que permitiu o conhecimento e o estudo de um vasto patrimônio oral está acessível em: <http://www.culturalquity.org/ lomaxgeo>.

${ }^{10}$ Grotowski escreveu: "Quando se trabalha sobre um canto muito vivo, não é sobre a possessão que é preciso pensar, é preciso pensar no canto como uma pessoa. [...] O canto como pessoa, não é a pessoa que canta, não é a pessoa que cantou primeiro, não é a pessoa que criou o canto: o canto é uma pessoa, e cantando eu devo descobrir isso" (Brook, 2009, p. 135). 


\section{Referências}

ATTISANI, Antonio (Org.). Jerzy Grotowski. L’eredità vivente. Turin: Accademia University Press, 2013.

BIAGINI, Mario. L'Humain en Action au Workcenter of Jerzy Grotowski and Thomas Richards, conférence à l'Université de Caen Basse-Normandie en dialogue avec Eric Vautrin. In: ATTISANI, Antonio (Org.). Jerzy Grotowski. L'eredità vivente. Turin: Accademia University Press, 2013.

BROOK, Peter. Dialogue entre Peter Brook et Jerzy Grotowski. In: BROOK, Peter. Avec Grotowski. Arles: Actes Sud, 2009. P. 111-137.

GROTOWSKI, Jerzy. Le Théâtre est une Rencontre. In: GROTOWSKI, Jerzy. Vers un Théâtre Pauvre. Paris: L'Âge d'homme, 1971. P. 53-58.

LISTA, Giovanni. Le Corps et la Scène Implosée. In: LISTA, Giovanni. La Scène Moderne. Paris: Editions Carré d'art, 1997; Arles: Actes Sud, 1997. P. 193-213.

MERVANT-ROUX, Marie-Madeleine. Un Espace Accidenté. Agôn [online], La Rupture, Lyon, n. 2, 2008-2010. Disponível em: <http://agon.ens-lyon.fr/index.php?id=1076>. Acesso em: 05 jan. 2010.

Éric Vautrin é professor em Estudos Teatrais na Université de Caen Basse-Normandie, membro do grupo de pesquisas LASLAR (Unicaen, EA4256, "Lettres, Langues, Arts") e pesquisador associado no ARIAS-CNRS. Suas pesquisas se ocupam da representação teatral contemporânea; seus trabalhos recentes tratam do cruzamento entre Estética, História da Arte e Antropologia, tentando religar a história das formas e das técnicas, relaçóes teatrais, práticas de criação e bases simbólicas e institucionais. Ele é corresponsável pelo projeto internacional Mots et concepts du son au théâtre (ARIAS-CNRS).

E-mail: eric.vautrin@unicaen.fr

Traduzido do original em francês por Thiago Mattos de Oliveira (Universidade Federal Fluminense) e revisado por Dominique M. P. G. Boxus (Universidade Federal Fluminense). Revisão técnica de Tatiana Motta Lima (Universidade Federal do Estado do Rio de Janeiro).

Recebido em 29 de outubro de 2012

Aprovado em 10 de dezembro de 2012 